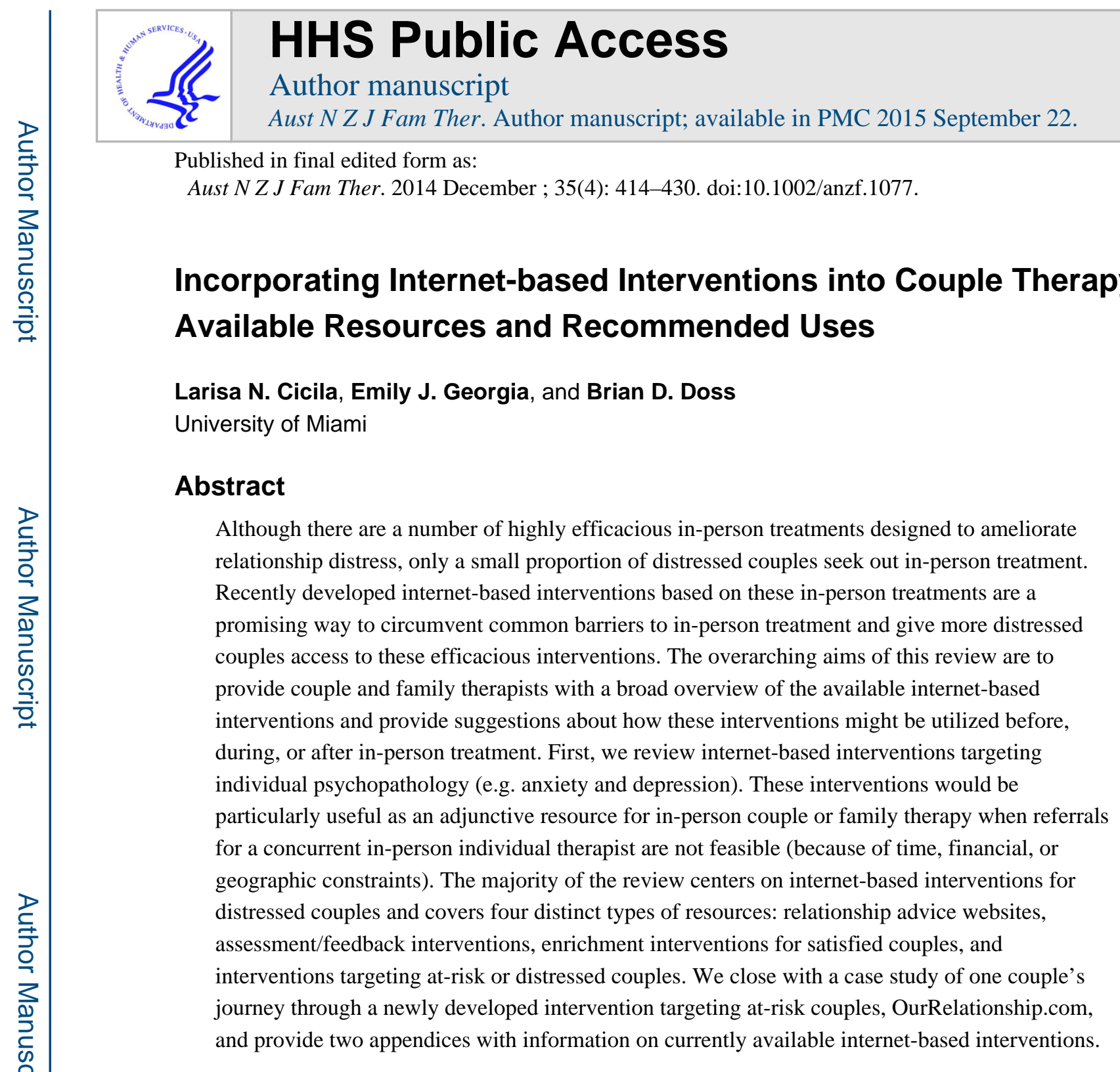

\title{
Keywords
}

internet-based interventions; online; dissemination; couple therapy; marital distress

High levels of marital distress have been linked to a variety of negative outcomes, including higher incidences of individual psychopathology (e.g., Whisman, 2007), poorer physical health (e.g., Robles, Slatcher, Trombellow, \& McGinn, 2014) and greater impairments in work and social life (e.g. Whisman \& Uebelacker, 2006). However, despite the fact that inperson couple therapy has been shown to be effective in reducing relationship distress (Lebow, Chambers, Christensen \& Johnson, 2012), only a small portion of couples seek

\footnotetext{
Although not a web-based intervention, Couple CARE is an enrichment program that is currently free to Australian couples (through the recent "Relationships Australia" initiative). Couple CARE involves DVDs and workbooks that are completed in the home as well as weekly check-ins with a Relationship Educator. The course takes about 12 hours spread out over 6 weeks to complete. Couple CARE has been shown to be effective in several research trials, including for couples in the general community (Halford, Moore, Wilson, Farrugia, \& Dyer, 2004) and for new parents (Petch, Halford, Creedy, \& Gamble, 2012). For more information, please visit http://www.raq.org.au/education/course-regular/couple-care.
} 
treatment. Recent estimates found that only $19 \%$ of intact couples seek any type of counseling or therapy for their relationship and that only $37 \%$ of divorced couples sought any couple therapy prior to divorcing (Johnson et al., 2002). These findings mirror low levels of treatment-seeking for clinically significant individual psychopathology (Andrade et al., 2014), again despite the availability of effective treatments for a wide variety of disorders (APA, 2006). Commonly cited barriers to seeking mental health treatment, whether for individual or couple therapy, include perceived stigma, financial burden, and logistical concerns, such as difficulty scheduling appointments or finding transportation to appointments (Hoge et al., 2004).

One promising option for circumventing these treatment barriers is to translate these effective interventions into a format that can be delivered via the internet. With $70 \%$ of households in the United States reporting broadband / cable internet access in 2013 (and similar or even higher rates in Australia, New-Zealand, and Western European countries), web-based delivery of interventions has become an increasingly viable option for increased dissemination of evidence-based treatments (File, 2013; International Telecommunication Union, 2012). Internet-based interventions provide individuals with a highly accessible (24 hours/ 7 days a week) intervention they can complete in the privacy of their own homes, thus circumventing barriers related to transportation, scheduling conflicts, and perceived stigma. From a dissemination perspective, internet-based interventions have the potential to reach a large population at a relatively low-cost, including underserved populations that may not have access to in-person therapy because of financial or geographic limitations.

The majority of available internet-based interventions available for use by individuals or couples are translations of evidence-based, in-person therapies. These interventions generally involve minimal therapist contact, often through asynchronous e-mail communication (Newman, Erickson, Przeworski \& Dsuz, 2003) and guide individuals through an interactive self-help program that can incorporate text and multimedia content to varying extent. Internet-based interventions have the potential to be highly personalized for a diverse group of users as well as easily updated, refined and expanded according to the latest research findings (Amstadter, Broman-Fulks, Zinzow, Ruggiero \& Cercone, 2009; Christensen, Batterham \& Calear, 2014).

While some concerns have been raised about reduced efficacy for internet-based interventions, multiple randomized trials have found similar effect sizes between internetbased interventions and face-to-face treatments for depression and anxiety (Andrews, Cuijpers, Craske, McEvoy \& Titov, 2010; Cuijpers, Donker, van Straten, Li \& Andersson, 2010). Additionally, some fear that the largely self-guided nature of these interventions would lead to low completion rates; however, studies have found that contact with personnel prior to starting the internet-based intervention (e.g., a structured interview) and clear deadlines for completion aided in increasing completion rates (Andersson \& Johansson, 2012). Indeed, governments in the United Kingdom, Sweden and Australia have formally endorsed the use of internet-based interventions like Fearfighter (panic and anxiety; Marks, Kenwright, McDonough, Whittaker \& Mataix-Cols, 2004; Schneider, Mataix-Cols, Marks, $\&$ Bachofen, 2005), Beating the Blues (depression and anxiety; Proudfoot et al., 2004), MyCompass (stress, anxiety and depression; Proudfoot et al., 2013) and MoodGYM 
(depression prevention for young people; Calear, Christensen, Mackinnon, Griffiths \& O'Kearney, 2009). These interventions are accessible either through primary care or directly through online portals (see Appendix A).

Within the couples field, a recent meta-analysis found that blended programs, which combined self-directed and more traditional educational components (e.g. in-person classes), significantly impact relationship quality (Cohen's $d=0.43, p<.01$ ) and communication skills (Cohen's $d=0.72, p<.05$ ). Moreover, the blended programs outperformed traditional, inperson education (McAllister, Duncan \& Hawkins, 2012). In contrast, purely self-directed marriage and relationship education programs (those without in-person contact) for couples led to extremely small, non-significant effects on relationship quality (Cohen's $d=0.03$ ) and extremely small, yet significant (Cohen's $d=0.03, p<.05$ ), effects on communication skills.

\section{Aims of the this Article}

This paper endeavors to outline several other ways that internet-based interventions could be utilized by a couple or family therapist, whether as a prelude to in-person therapy, a resource for homework during treatment, or as a tool to maintain gains after treatment. To this end, we will focus primarily on web-based resources specifically targeting relationship distress. To illustrate the nature of web-based interventions, we present a case study of a couple who completed the internet-based OurRelationship.com program, a translation of Integrative Behavioral Couple Therapy (IBCT), before seeking in-person couple therapy. We will then briefly review web-based interventions for individuals, as these interventions may serve as an important referral resource for partners experiencing individual mental health issues Finally, the appendices provide a quick-reference guide for internet-based interventions for couples and individuals that are currently available, as well as recommendations with how to incorporate these resources into in-person therapy.

\section{Internet-based Interventions for Couples}

A number of web-based resources and interventions have been developed to improve relationship distress. These internet resources tend to fall into four different categories: relationship advice websites, assessment/feedback sites, enrichment interventions for satisfied couples, and interventions targeting at-risk or distressed couples. These resources differ in terms of the services they offer and the type of couple they serve; as a result, they will have differential utility before, during, or following in-person couple therapy (see Appendix B).

\section{Relationship advice websites}

Relationship advice websites are the most popular internet-based resources that couples seek out on their own (Georgia \& Doss, 2013). Most of these sites cover a wide variety of topics for couples at all relationship stages (e.g. dating, cohabiting, engaged, married etc.) and present relationship advice in the form of articles and videos. Common topics that are addressed include ways to enhance emotional intimacy, communicate more effectively, navigate parenting disputes, cope with infidelity and improve sexual satisfaction within the relationship. 
These websites vary in terms of whether experts are dispensing advice, or whether couples are sharing their own experiences. For example, one popular relationship advice website, www.TwoOfUs.org, was founded through a grant from the United States' Department of Health and Human Resources and is currently maintained by the National Healthy Marriage Resource Center. It has a video library where trained experts (e.g. clinical psychologists, counselors, sociologists, pastors) filmed short clips about popular relationship topics, as well as articles based on empirical findings. TheCoupleConnection.net, based in the United Kingdom, was established and is run by OnePlusOne, a non-profit organization. It is another comprehensive website that includes articles, assessments, activities, quizzes and exercises, as well as forums that are moderated by a team of counsellors. Similar sites include the Resources section of the Relationships Aoetearoa website, a non-profit organization based in New Zealand, and the Relationship Advice section of the Relationships Australia website, which is run by the Australian Department of Families, Community Services and Indigenous Affairs. Furthermore, these websites can serve as a portal to find available in-person couple therapy in those area. However, the most popular sites (as measured by website visits) are the sites where couples post responses to other couples' problems - sites such as TalkAboutMarriage.com. As these types of sites are generally not actively monitored by relationship experts, we hesitate to recommend them as a resource for couples.

Informational websites run or monitored by relationship experts are likely most helpful to couples early in the help-seeking process (e.g., premarital or enrichment programs) perhaps as a place to seek out additional resources or help couples identify certain aspects of their relationship that are problematic (e.g., interpersonal violence) and encourage them to seek couples therapy. Alternatively, informational websites may also serve as a useful resource following termination of couple therapy by refreshing couples on important concepts learned during treatment (e.g. effective communication, problem-solving). Used in this way, they could potentially aide in maintaining gains achieved during treatment.

\section{Assessment/feedback Internet-based interventions}

Assessment/feedback internet-based interventions involve couples completing questionnaires that assess a wide variety of factors that could impact relationship quality, including individual personality traits, communication and conflict resolution skills, family backgrounds and personal values. Results from these questionnaires are often presented to the couple using graphs and text, with findings grouped into areas of strengths (protective factors) and challenges (risk factors). These types of interventions are attractive because they are cost-efficient, highly accessible, and can be used at numerous stages of in-person couple therapy. For example, a couple could complete an assessment/feedback intervention before presenting to therapy to either provide the therapist with a means to screen out problems that are best handled by a referral or to present a comprehensive initial formulation for the therapist prior to meeting the couple in person. Assessment/feedback interventions could also be used multiple times throughout therapy, with results before treatment serving as a baseline and subsequent assessments demonstrating areas of progress. We identified three empirically-based assessment and feedback systems currently available online. 
The 276-item Relationship Evaluation Questionnaire (RELATE; Busby, Holman and Taniguchi, 2001) is an online questionnaire that focuses on assessing a variety of areas that often impact relationship satisfaction including personality traits, values, support from family and friends, communication skills, and one's upbringing. After completing the questionnaire, couples are provided with an 11-12 page report that compares and summarizes their answers in terms of their personality traits, their attitudes on a number of important topics (e.g. children, religion, roles), and identifies not only problem areas but also areas of strength. Finally, tailored suggestions for improving the relationship and other resources to seek are provided.

One small randomized control trial (RCT) investigating the efficacy of RELATE found that therapist interpretation of an internet-based assessment/feedback intervention produced superior results compared to a control group (Larson, Vatter, Galbriath, Holman \& Stahmann, 2007). Specifically, couples with one, two-hour interpretation session with a therapist demonstrated higher relationship satisfaction, commitment and more positive opinions, feelings and increased readiness for marriage up to 60 days after completing the initial questionnaire. Researchers also examined couple functioning in a condition where couples interpreted feedback from the RELATE questionnaire without the assistance of a therapist. While couples in the self-interpretation group had lower scores on the dependent variables immediately after the intervention (vs. therapist and control groups), only the two active intervention conditions showed improvement on these variables during the 60 day follow-up period. These results may suggest that assessment/feedback interventions are most effective when used in conjunction with therapist interpretation, but that there are no ill effects from interpreting feedback without a professional. Another factor that increases the efficacy of RELATE (at least for women) is the addition of a 10-12 hour long relationship skills training program that couples complete in their own home using a DVD, guidebook, and weekly phone appointments with a psychologist. Women in the RELATE + relationship skills condition demonstrated more improvements in communication and relationship satisfaction across 12 months of follow-up than women in the RELATE only condition. Men reported high quality of communication and relationship satisfaction, but their scores did not differ across groups (Halford et al., 2010).

Two additional internet-based assessment/feedback interventions are translations of paperbased systems. Both FOCCUS (Facilitating Open Couple Communication, Understanding and Study; Markey, Micheletto \& Becker, 1997) and PREPARE/ENRICH (Olson \& Olson, $1999)$ are extensive $(150+$ item) online adaptations of paper-based assessments. Both paper measures have been shown to have high internal consistency (.74-.98) and have shown some predictive utility for some aspects of marital satisfaction and continuity (Fowers, Montel \& Olson, 1996; Williams \& Jurich, 1995). However, the online version of these systems have yet to be tested.

\section{Enrichment interventions targeting satisfied couples}

Interventions targeting premarital, newlywed, or otherwise generally satisfied couples tend to focus on psychoeducation around effective communication and problem-solving skills. These interventions tend to be more time-intensive than advice websites or assessment/ 
feedback interventions and often include exercises to not only teach skills, but also encourage couples to implement these relationship skills. Enrichment interventions could be used as an adjunct to couple or family therapy in a number of ways. First, they could be a useful resource for homework assignments during in-person couple therapy. For instance, after communication skills are introduced in session, a couple could use activities from an enrichment intervention to reinforce what they learned in session and guide them in implementing the skills outside of session. Enrichment intervention programs could also be used after couple therapy as an additional resource for topics not covered during treatment or as a means to maintain gains.

The most studied computer-based enrichment intervention is ePREP (Braithwaite \& Fincham, 2007), a translation of the Prevention and Relationship Enhancement Program (PREP; Markman, Stanley, \& Blumberg, 2001). Broadly, ePREP teaches couples how to recognize and combat risk factors that are amenable to intervention, like negative patterns of conflict, communication difficulties and low levels of commitment. Major targets of this intervention include improving communication, problem solving skills and enhancing relationship positives. Results from RCTs found that ePREP participants experienced greater reductions in individual psychopathology (e.g. depression \& anxiety; Braithwate \& Fincham, 2007; Braithwate \& Fincham, 2009) and improvements in several areas of relationship functioning, including constructive communication (Braithwate \& Fincham, 2007; Braithwate \& Fincham, 2011) and physical and psychological aggression (Braithwate $\&$ Fincham, 2007; 2009, 2011) up to 10 months after the intervention. However, there were inconsistent effects on relationship satisfaction, with some studies showing significant effects (Braithwaite \& Fincham, 2007, 2011) but not others (Braithwate \& Fincham, 2009).

While these results are certainly promising, there are two primary limitations to the current ePREP program. First, the intervention is computer- rather than internet-based and users in these studies came to the lab to complete the intervention (as such, it is not currently available to the public outside of these research studies). Second, the majority of the empirical studies of ePREP were completed on small samples of undergraduate students involved in relationships as brief as four months. However, most recently, ePREP was administered to one hundred couples in the community (Braithwaite \& Fincham, 2014). In this study, ePREP couples demonstrated lower levels of physical and psychological aggression compared to control couples and these gains were maintained through a one year follow-up assessment. Gains in communication or relationship satisfaction were not reported.

Several other web-based enrichment programs have also been tested. A four-week, internetbased intervention designed to increase romantic relationship excitement was tested in a community sample of Australian couples. This program led to higher levels of romantic relationship excitement, positive affect, and relationship satisfaction when compared to a waitlist control group (Coulter \& Malouff, 2013). Additionally, a separate study explored the couple functioning in couples that were randomized to either a different internet-based intervention, a traditional couple workshop, or a waitlist control group. The internet-based intervention prompted couples to read scholarly relationship articles and complete $2-3$ online exercises over the course of six weeks, whereas couples randomized to the traditional 
workshop group attended weekly two-hour long workshops for six weeks. Results found significant gains in empathic communication and relationship satisfaction for both the internet-based intervention and a 12-hour traditional workshop when compared to the waitlist control group, where couples showed significant deterioration. Furthermore, gains at post-treatment were not statistically different between the internet-based intervention and the traditional workshop intervention (Duncan, Steed, \& Needham, 2009). While not as widely studied, one enrichment program that is currently available online has been shown to create positive impacts on couple functioning. The internet-based program, Power of Two Online, was tested in a sample of new or expectant parents in the United States. Couples in the intervention reported higher marital satisfaction and improved conflict management than couples in a waitlist control group (Kalinka, Fincham, \& Hirsch, 2012). ${ }^{1}$

\section{Interventions targeting at-risk or distressed couples}

An additional category of interventions focuses on at-risk couples or couples who are experiencing relationship distress, but are not in an acute crises (e.g., recent affair revelation) or have imminent divorce plans. These interventions are generally more timeintensive than enrichment intervention programs. Such interventions targeting at-risk or distressed couples may be the most versatile and valuable type of program for practicing clinicians, particularly if there are constraints on number of sessions with a couple.

For example, within an organization that often has long wait-list before couples can be seen in-person, one could offer a web-based program prior to initiating in-person therapy. Utilizing a program in this way would hopefully halt any further declines in relationship functioning as well as provide the couple with an orientation to the concepts associated with couple therapy, like the mutuality of relationship difficulties. As another example, if there are limitations imposed on treatment length, such as insurance limits or difficulties with transportation, a clinician could use these types of programs to augment sessions throughout treatment and reduce the overall time spent in in-person therapy. For example, a clinician could ask a couple to complete an assessment/feedback portion of a program targeting atrisk or distressed couples prior to coming to an initial in-person intake. At the intake session, a clinician could provide them with an interpretation of their feedback report and then help them identify one relationship difficulty to target. Then, the couple could complete online activities outside of session to help them develop a more objective, mutual understanding of the target problem. After completing these activities, the couple could then present to inperson therapy to have a mediated, more effective conversation about what they have learned. Finally, an intervention targeting at-risk and distressed couples could also be useful post-treatment if, because of aforementioned limitations, certain topics that are significant problems in the relationship were not able to be addressed.

The only published RCT of an intervention targeting at-risk or distressed couples compared the effects of an internet-based program to an in-person brief sex counseling program; participants included couples where the man had recently undergone treatments for prostate cancer and was experiencing difficulties with sexual functioning (Schover et al., 2013). Both programs included exercises to improve sexual communication, increase comfort in initiating sexual activity and facilitate resuming sex without performance anxiety. Across 
both active interventions, men experienced improvements in erectile functioning and women who reported significant sexual distress at baseline showed significant improvements in sexual functioning. Moreover, there were no differences in efficacy between the internetbased program and the brief in-person intervention.

Although results are not yet published, a secondary prevention program funded by the United States' National Institutes of Health - OurRelationship.com - has shown promising results in a recently-completed RCT in a nationally-representative sample of 300 distressed couples (Doss, Georgia, Cicila, Benson \& Christensen, 2014). While many of the resources we have described thus far are grounded in cognitive-behavioral principles and focus on skill-building exercises, OurRelationship.com focuses more on increasing acceptance and empathy towards relationship difficulties. OurRelationship.com is an internet-based translation of Integrative Behavioral Couple Therapy, a highly efficacious in-person couple therapy (Christensen, Atkins, Berns, Wheeler, Baucom \& Simpson, 2004; Christensen, Atikins, Baucom \& Yi, 2010; Christensen, Atkins, Yi, Baucom \& George, 2006).

The OurRelationship.com program takes couples through three self-guided phases of treatment: 1) an Observe phase where they decide on a relationship core issue to focus on for the rest of the program 2) an Understand phase where they develop a tailored, objective analysis of their core issue and, finally, 3) a Respond phase where they brainstorm behavioral solutions tailored to their core issue. Both members of a couple complete the 5-6 hour program during the same 4-6 week time period; however, many of the activities are done individually rather that together in front of the computer. At the end of each of the three phases, the program guides couples through a joint conversation where they share and discuss what they worked on during the individual activities. To aide in timely completion of the program and to help couples tailor the program to their relationship core issue, "coaches" have four videoconference appointments with couples during the course of the program (total personnel contact per couple: roughly1 hour).

\section{OurRelationship.com Case Study}

To illustrate how the OurRelationship.com program can benefit couples in the short-term and encourage them to seek more intensive, in-person therapy in the long-term, we will detail one representative couple's progress through the program (identifying information has been changed to protect confidentiality). Kurt ( 35 years old) and Kayla ( 29 years old) were a heterosexual couple living in the United States who had been married for a little over a year when they began the program. They each had two children from previous relationships, for a total of four children, and were married six months after they met each other. At the start of the program, both partners independently identified their most significant relationship difficulty as "trust." Kayla reported that this issue was an "extreme problem" and Kurt stated that it was a "big problem". Neither partner reported feeling particularly optimistic about their ability to handle this issue effectively, with both couples reporting that they disagreed with the statement "I believe we can successfully handle conflicts that come up around the biggest problem I identified." About three months before beginning the program, Kayla found romantic and sexual text messages between Kurt and several exotic dancers from a gentleman's club he had been visiting with increasing regularity. Both partners reported that 
Kurt was more likely to visit this gentleman's club and reach out to these dancers when he was under a lot of external stress. During the conversation at the end of the Observe phase, they agreed that "trust" was the core issue in their relationship they would like to work on during the course of the program. During their Skype appointment with their coach, they were encouraged to make sure that their definition of "trust" was as specific as possible and tied to behaviors, so that they would be able to develop a detailed, objective analysis of the core issue in the Understand phase of the program.

During the Understand phase of the program, Kayla and Kurt developed a DEEP Understanding of their core issue, where they explored how Differences in key personality traits, different Emotions (including surface emotions, like anger, and hidden, vulnerable emotions, like feeling hurt), External stress and Patterns of Communication impact their core issue of "trust". The impact of past experiences, as well as the hidden emotions that were triggered when discussing the core issue, were both integral to Kayla and Kurt's newly developed DEEP Understanding. For Kayla, she realized that being cheated on in past relationships led her to react with stronger emotions to Kurt's behaviors. Kurt was able to identify that underneath the anger and frustration he initially expressed when this core issue arose, he felt "embarrassed and ashamed" about his interactions with these other women. After their Understand conversation, both partners reported feeling more confident in their ability to handle their core issue effectively.

In the final Respond phase of the program, the couple brainstormed solutions tailored to their core issue, including the fact that Kurt needed to no longer visit gentleman's clubs or contact exotic dancers. After completing this final phase of the program, both partners reported that they felt that "many positive improvements" had been made, both in terms of their own and their partner's behaviors. In addition, they reported significantly higher levels of confidence around their ability to handle their core issue effectively (vs. reports prior to beginning the program). Perhaps most importantly, both Kayla and Kurt reported higher relationship satisfaction at the end of the program. While both Kayla and Kurt reported benefits at the end of the program, they also reported that they had decided to seek in-person couple therapy to continue working on their difficulties surrounding trust and infidelity.

\section{Internet-based Interventions for Individual Psychopathology}

Within the context of couple therapy, web-based interventions for individuals may be particularly useful if one member of the couple has significant psychopathology that would be better addressed outside of a conjoint session. For example, depending on the setting, the average individual presenting for couple therapy reports symptoms of depression in the mild (in private practice; Atkins, Dimidjian, Bedics, \& Christensen, 2009) to clinical range (in a military veteran hospital setting; Rowe, Doss, Hsueh, Libet, \& Mitchell, 2011). Whereas traditional wisdom would dictate that the individual would need a referral to a concurrent individual therapist to address this psychopathology (or delaying couple therapy until the individual problem had been addressed), couple and family therapists may instead suggest an adjunctive individual internet-based intervention, which would likely be less of a burden on the couple's finances and time. 
There are a number of available internet based interventions that target depression, anxiety and drug/alcohol abuse, all of which are common comorbidities of relationship distress (e.g. Whisman, 2007). Overall, these internet-based interventions tend to be efficacious, with meta-analyses showing small, but significant, effects on depression (Cohen's $d=0.41$; Andersson \& Cuijpers, 2009) and larger effects on anxiety disorders (Cohen's d $=0.92$ for social phobia [n=8], d = 0.83 for panic disorder [n=6], $d=1.12$ for GAD [n=2]; Andrews et al., 2010). Unfortunately, internet-based interventions targeting alcohol/drug abuse have not shown similarly strong effects on average (Cohen's $d=0.20$; Rooke, Thorsteinsson, Karpin, Copeland \& Allsop, 2010). Therefore, if there is a substantial drug or alcohol difficulty interfering with a focus on the couple relationship (or serving as the primary cause of relationship distress), referral for in-person treatment rather than internet-based treatment may be warranted.

Although most of these treatments focused on individual psychopathology are efficacious on average, several important moderators have been identified, particularly in programs targeting depression. Treatments with more personnel support before, during and after treatment created significantly larger reductions in depression (Cohen's $d=0.76$ ) than interventions with no personnel support (Cohen's $d=0.21$; Johansson \& Andersson, 2012). Additionally, treatments that are tailored to each participant's presenting problem(s) produce superior results in patients with severe forms of depression when compared to non-tailored interventions (Johansson et al., 2012). Given these moderators, a tailored intervention with high levels of personnel contact are likely to lead to significant improvement; thus, these characteristics are included in the descriptions of individual programs in Appendix A.

\section{Conclusion}

Internet-based interventions are a promising avenue for wider dissemination of evidencebased treatments. As we have demonstrated in this review, there are a number of exciting possibilities for incorporating these internet-based interventions into in-person couple therapy. There are numerous internet-based interventions designed to improve couple functioning, ranging from relationship advice websites to time-intensive interventions targeting at-risk or distressed couples (see Appendix B). There are also a variety of efficacious interventions targeting individual psychopathology (e.g. anxiety and depression; see Appendix A) that might be particularly useful for concurrent, adjunctive use with inperson couple therapy. These individual web-based interventions may be especially helpful to the couples therapist particularly when individual referrals are limited because of time, financial, or geographic constraints. Here, we have outline various ways these interventions could be utilized before, during or after in-person couple therapy to either 1) improve efficacy of the in-person therapy or 2) reduce clinician time spent with a couple, which could be particularly important if there are time-constraints imposed by insurance limitations or lack of resources available to couples (see Appendix C).

\section{References}

Amstadter AB, Broman-Fulks J, Zinzow H, Ruggiero KJ, Cercone J. Internet-based interventions for traumatic stress-related mental health problems: A review and suggestion for future research. Clinical Psychology Review. 2009; 29(5):410-420.10.1016/j.cpr.2009.04.001 [PubMed: 19403215] 
Andrade LH, Alonso JJ, Mneimneh ZZ, Wells JE, Al-Hamzawi AA, Borges GG, Kessler RC. Barriers to mental health treatment: Results from the WHO World Mental Health surveys. Psychological Medicine. 2014; 44(6):1303-1317.10.1017/S003329171300194 [PubMed: 23931656]

APA. American Psychiatric Association Practice Guidelines for Treatment of Psychiatric Disorders: Compendium. American Psychiatric Association Press; Arlington, VA: 2006.

Andersson G, Cuijpers P. Internet-based and other computerized psychological treatments for adult depression: A meta-analysis. Cognitive Behaviour Therapy. 2009; 38(4):196205.10.1080/16506070903318960 [PubMed: 20183695]

Andrews G, Cuijpers P, Craske MG, McEvoy P, Titov N. Computer therapy for the anxiety and depressive disorders is effective, acceptable and practical health care: A meta-analysis. Plos ONE. 2010; 5(10)10.1371/journal.pone.0013196

Atkins DC, Dimidjian S, Bedics JD, Christensen A. Couple discord and depression in couples during couple therapy and in depressed individuals during depression treatment. Journal of Consulting and Clinical Psychology. 2009; 77:1089-1099.10.1037/a0017119 [PubMed: 19968385]

Braithwaite SR, Fincham FD. ePREP: Computer based prevention of relationship dysfunction, depression and anxiety. Journal of Social and Clinical Psychology. 2007; 26(5):609-622.10.1521/ jscp.2007.26.5.609

Braithwaite SR, Fincham FD. A randomized clinical trial of a computer based preventive intervention: Replication and extension of ePREP. Journal of Family Psychology. 2009; 23(1):32-38.10.1037/ a0014061 [PubMed: 19203157]

Braithwaite SR, Fincham FD. Computer-based dissemination: A randomized clinical trial of ePREP using the actor partner interdependence model. Behaviour Research and Therapy. 2011; 49(2):126131.10.1016/j.brat.2010.11.002 [PubMed: 21159326]

Braithwaite SR, Fincham FD. Computer-based prevention of intimate partner violence in marriage. Behaviour Research and Therapy. 2014; 54:12-21.10.1016/j.brat.2013.12.006 [PubMed: 24463577]

Busby DM, Holman TB, Taniguchi N. RELATE: Relationship evaluation of the individual, family, cultural, and couple contexts. Family Relations. 2001; 50(4):308-316.

Calear AL, Christensen H, Mackinnon A, Griffiths KM, O'Kearney R. The YouthMood Project: A cluster randomized controlled trial of an online cognitive behavioral program with adolescents. Journal of Consulting and Clinical Psychology. 2009; 77(6):1021-1032.10.1037/a0017391 [PubMed: 19968379]

Christensen A, Atkins DC, Baucom B, Yi J. Marital status and satisfaction five years following a randomized clinical trial comparing traditional versus integrative behavioral couple therapy. Journal of Consulting and Clinical Psychology. 2010; 78(2):225-235.10.1037/a0018132 [PubMed: 20350033]

Christensen A, Atkins DC, Berns S, Wheeler J, Baucom DH, Simpson LE. Traditional versus Integrative Behavioral Couple Therapy for significantly and chronically distressed married couples. Journal of Consulting and Clinical Psychology. 2004; 72(2):176191.10.1037/0022-006X.72.2.176 [PubMed: 15065953]

Christensen A, Atkins DC, Yi J, Baucom DH, George WH. Couple and individual adjustment for 2 years following a randomized clinical trial comparing traditional versus integrative behavioral couple therapy. Journal of Consulting and Clinical Psychology. 2006; 74(6):11801191.10.1037/0022-006X.74.6.1180 [PubMed: 17154747]

Christensen H, Batterham P, Calear A. Online interventions for anxiety disorders. Current Opinion in Psychiatry. 2014; 27(1):7-13.10.1097/YCO.0000000000000019 [PubMed: 24257123]

Coulter K, Malouff JM. Effects of an intervention designed to enhance romantic relationship excitement: A randomized-control trial. Couple and Family Psychology: Research and Practice. 2013; 2(1):34-44.10.1037/a0031719

Cuijpers PP, Donker TT, van Straten AA, Li JJ, Andersson GG. Is guided self-help as effective as face-to-face psychotherapy for depression and anxiety disorders? A systematic review and metaanalysis of comparative outcome studies. Psychological Medicine. 2010; 40(12):19431957.10.1017/S0033291710000772 [PubMed: 20406528] 
Doss, BD.; Georgia, EJ.; Cicila, LN.; Benson, LA.; Christensen, A. Effects of OurRelationship.com, a brief web-based intervention, on relationship functioning. In: Doss, BD., Chair, editor. Brief interventions for at-risk and distressed couples; Symposium conducted at the meeting of the Association for Behavioral and Cognitive Therapies; Philadelphia, PA. 2014 Nov.

Duncan SF, Steed A, Needham CM. A comparison evaluation study of web-based and traditional marriage and relationship education. Journal of Couple \& Relationship Therapy. 2009; 8:162180.10.1080/15332690902813836

File, Thom. Current Population Survey Reports. U.S. Census Bureau; Washington, DC: 2013. Computer and Internet Use in the United States; p. P20-568.(http://www.census.gov/prod/ 2013pubs/p20-569.pdf)

Fowers BJ, Montel KH, Olson DH. Predicting marital success for premarital couple types based on PREPARE. Journal of Marital \& Family Therapy. 1996; 22(1):103-119.

Georgia EJ, Doss BD. Web-based couple interventions: Do they have a future? Journal of Couple \& Relationship Therapy. 2013; 12(2):168-185.10.1080/15332691.2013.779101

Halford WK, Moore E, Wilson KL, Farrugia C, Dyer C. Benefits of flexible delivery relationship education: An evaluation of the couple CARE program. Family Relations. 2004; 53:469476.10.1111/j.0197-6664.2004.00055.x

Halford WK, Wilson K, Watson B, Verner T, Larson J, Busby D, Holman T. Couple relationship education at home: Does skill training enhance relationship assessment and feedback? Journal of Family Psychology. 2010; 24(2):188-196.10.1037/a0018786 [PubMed: 20438194]

Hoge CW, Castro CA, Messer SC, McGurk D, Cotting DI, Koffman RL. Combat duty in Iraq and Afghanistan, mental health problems, and barriers to care.[see comment]. New England Journal of Medicine. 2004; 351(1):13-22. [PubMed: 15229303]

Holländare FF, Johnsson SS, Randestad MM, Tillfors MM, Carlbring PP, Andersson GG, Engström II. Randomized trial of internet-based relapse prevention for partially remitted depression. Acta Psychiatrica Scandinavica. 2011; 124(4):285-294.10.1111/j.1600-0447.2011.01698.x [PubMed: 21401534]

International Telecommunication Union. Fixed (wired)-broadband subscriptions per 100 inhabitants 2012. Dynamic Report, ITU ITC EYE. 2012 Retrieved on 29 June 2013.

Johansson R, Andersson G. Internet-based psychological treatments for depression. Expert Review of Neurotherapeutics. 2012; 12(7):861-870.10.1586/ern.12.63 [PubMed: 22853793]

Johansson R, Sjöberg E, Sjögren M, Johnsson E, Carlbring P, Andersson T, Andersson G. Tailored vs. standardized internet-based cognitive behavior therapy for depression and comorbid symptoms: A randomized controlled trial. Plos ONE. 2012; 7(5)10.1371/journal.pone.0036905

Johnson, CA.; Stanley, SM.; Glenn, ND.; Amato, PR.; Nock, SL.; Markman, HJ., et al. Marriage in Oklahoma: 2001 baseline statewide survey on marriage and divorce (S02096 OKDHS). Oklahoma City, OK: Oklahoma Department of Human Services; 2002.

Kalinka CJ, Fincham FD, Hirsch AH. A randomized clinical trial of online-biblio relationship education for expectant couples. Journal of Family Psychology. 2012; 26(1):159-164.10.1037/ a0026398 [PubMed: 22309819]

Kessler D, Lewis G, Kaur S, Wiles N, King M, Weich S, Peters TJ. Therapist-delivered internet psychotherapy for depression in primary care: A randomised controlled trial. The Lancet. 2009; 374(9690):628-634.10.1016/S0140-6736(09)61257-5

Larson JH, Vatter RS, Galbraith RC, Holman TB, Stahmann RF. The relationship evaluation (RELATE) with therapist-assisted interpretation: Short term effects on premarital relationships. Journal of Marital and Family Therapy. 2007; 33:364-374. [PubMed: 17598783]

Lebow JL, Chambers AL, Christensen A, Johnson SM. Research on the treatment of couple distress. Journal of Marital and Family Therapy. 2012; 38(1):145-168.10.1111/j.1752-0606.2011.00249.x [PubMed: 22283385]

Markey, B.; Micheletto, M.; Becker, A. Facilitating open couple communication, understanding, and study (FOCCUS). Omaha, Nebraska: Family Life Office, Archdiocese of Omaha; 1997.

Markman, H.; Stanley, S.; Blumberg, S. Fighting for Your Marriage (Revised and updated edition). San Francisco: Jossey Bass, Inc; 2001. 
Marks IM, Kenwright MM, McDonough MM, Whittaker MM, Mataix-Cols DD. Saving clinicians' time by delegating routine aspects of therapy to a computer: A randomized controlled trial in phobia/panic disorder. Psychological Medicine. 2004; 34(1):9-17.10.1017/S003329170300878X [PubMed: 14971623]

McAllister S, Duncan SF, Hawkins AJ. Examining the early evidence for self-directed marriage and relationship education: A meta-analytic study. Family Relations: An Interdisciplinary Journal of Applied Family Studies. 2012; 61(5):742-755.10.1111/j.1741-3729.2012.00736.x

Neubauer K, von Auer M, Murray E, Petermann F, Helbig-Lang S, Gerlach AL. Internet-delivered attention modification training as a treatment for social phobia: A randomized controlled trial. Behaviour Research and Therapy. 2013; 51(2):87-97.10.1016/j.brat.2012.10.006 [PubMed: 23262116]

Newman MG, Erickson T, Przeworski A, Dzus E. Self-help and minimal-contact therapies for anxiety disorders: Is human contact necessary for therapeutic efficacy? Journal of Clinical Psychology. 2003; 59(3):251-274.10.1002/jclp.10128 [PubMed: 12579544]

Olson, DH.; Olson, AK. PREPARE/ENRICH program: Version 2000. In: Hannah, MT., editor. Preventive approaches in couples therapy. Philadelphia, PA, US: Brunner/Mazel; 1999. p. 196-216.

Petch JF, Halford W, Creedy DK, Gamble J. A randomized controlled trial of a couple relationship and coparenting program (Couple CARE for Parents) for high- and low-risk new parents. Journal of Consulting and Clinical Psychology. 2012; 80(4):662-673.10.1037/a0028781 [PubMed: 22730950]

Proudfoot J, Clarke J, Birch M, Whitton AE, Parker G, Manicavasagar V, Hadzi-Pavlovic D. Impact of a mobile phone and web program on symptom and functional outcomes for people with mild-tomoderate depression, anxiety and stress: A randomised controlled trial. BMC Psychiatry. 2013; 1310.1186/1471-244X-13-312

Proudfoot J, Ryden C, Everitt B, Shapiro DA, Goldberg D, Mann A, Gray JA. Clinical efficacy of computerised cognitive-behavioural therapy for anxiety and depression in primary care: Randomised controlled trial. The British Journal of Psychiatry. 2004; 185(1):46-54.10.1192/bjp. 185.1.46 [PubMed: 15231555]

Robles TF, Slatcher RB, Trombello JM, McGinn MM. Marital quality and health: A meta-analytic review. Psychological Bulletin. 2014; 140(1):140-187.10.1037/a0031859 [PubMed: 23527470]

Rooke S, Thorsteinsson E, Karpin A, Copeland J, Allsop D. Computer-delivered interventions for alcohol and tobacco use: A meta-analysis. Addiction. 2010; 105(8):1381-1390.10.1111/j. 1360-0443.2010.02975.x [PubMed: 20528806]

Rose RD, Buckey, Zbozinek TD, Motivala SJ, Glenn DE, Cartreine JA, Craske MG. A randomized controlled trial of a self-guided, multimedia, stress management and resilience training program. Behaviour Research and Therapy. 2013; 51(2):106-112.10.1016/j.brat.2012.11.003 [PubMed: 23262118]

Rowe LS, Doss BD, Hsueh AC, Libet J, Mitchell AE. Coexisting difficulties and couple therapy outcomes: Psychopathology and intimate partner violence. Journal of Family Psychology. 2011; 25:455-458.10.1037/a0023696 [PubMed: 21534671]

Schneider AJ, Mataix-Cols D, Marks IM, Bachofen M. Internet-guided self-help with or without exposure therapy for phobic and panic disorders. Psychotherapy and Psychosomatics. 2005; 74(3): 154-164.10.1159/000084000 [PubMed: 15832066]

Schover LR, Canada AL, Yuan Y, Sui D, Neese L, Jenkins R, Rhodes MM. A randomized trial of Internet-based versus traditional sexual counseling for couples after localized prostate cancer treatment. Cancer. 2012; 118(2):500-509.10.1002/cncr.26308 [PubMed: 21953578]

Whisman MA. Marital distress and DSM-IV psychiatric disorders in a population-based national survey. Journal of Abnormal Psychology. 2007; 116(3):638-643.10.1037/0021-843X.116.3.638 [PubMed: 17696721]

Whisman MA, Uebelacker LA. Impairment and distress associated with relationship discord in a national sample of married or cohabiting adults. Journal of Family Psychology. 2006; 20(3):369377.10.1037/0893-3200.20.3.369 [PubMed: 16937993] 
Williams L, Jurich J. Predicting marital success after five years: Assessing the predictive validity of FOCCUS. Journal of Marital \& Family Therapy. 1995; 21(2):141-153. 


\section{Key Points}

1. Relationship advice websites are widely available but not empirically tested.

2. Assessment / feedback websites, which are brief in nature, have been found to positively impact relationship satisfaction and commitment as well as lead to more positive opinions, feelings and increased readiness for marriage. These interventions were found to be most effective when used in conjunction with therapist interpretation.

3. Enrichment interventions, which range from approximately $1-12$ hours in duration, lead to improvements in relationship satisfaction and constructive communication. These interventions also resulted in decreased individual psychopathology and reductions in physical and psychological aggression.

4. Online interventions targeting distressed couples have not been tested as widely; however the limited available published research and ongoing trials suggest its efficacy in improving relationship functioning and individual mental health.

5. Effective online interventions to improve depression, anxiety, and other individual problems may serve as an important adjunct to couple therapy. 


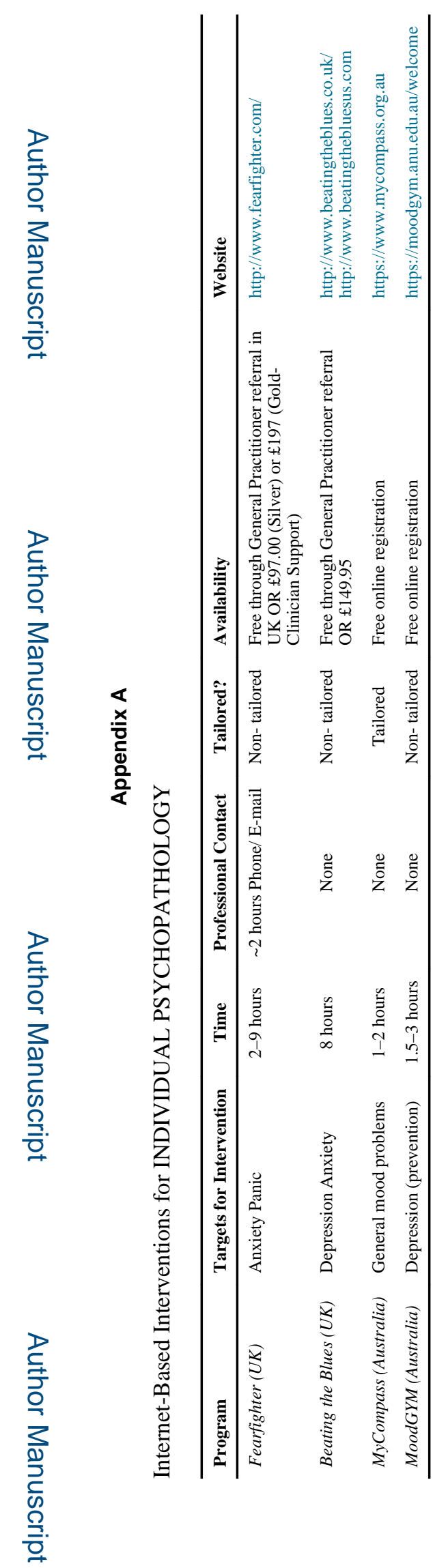

Aust N Z J Fam Ther. Author manuscript; available in PMC 2015 September 22. 


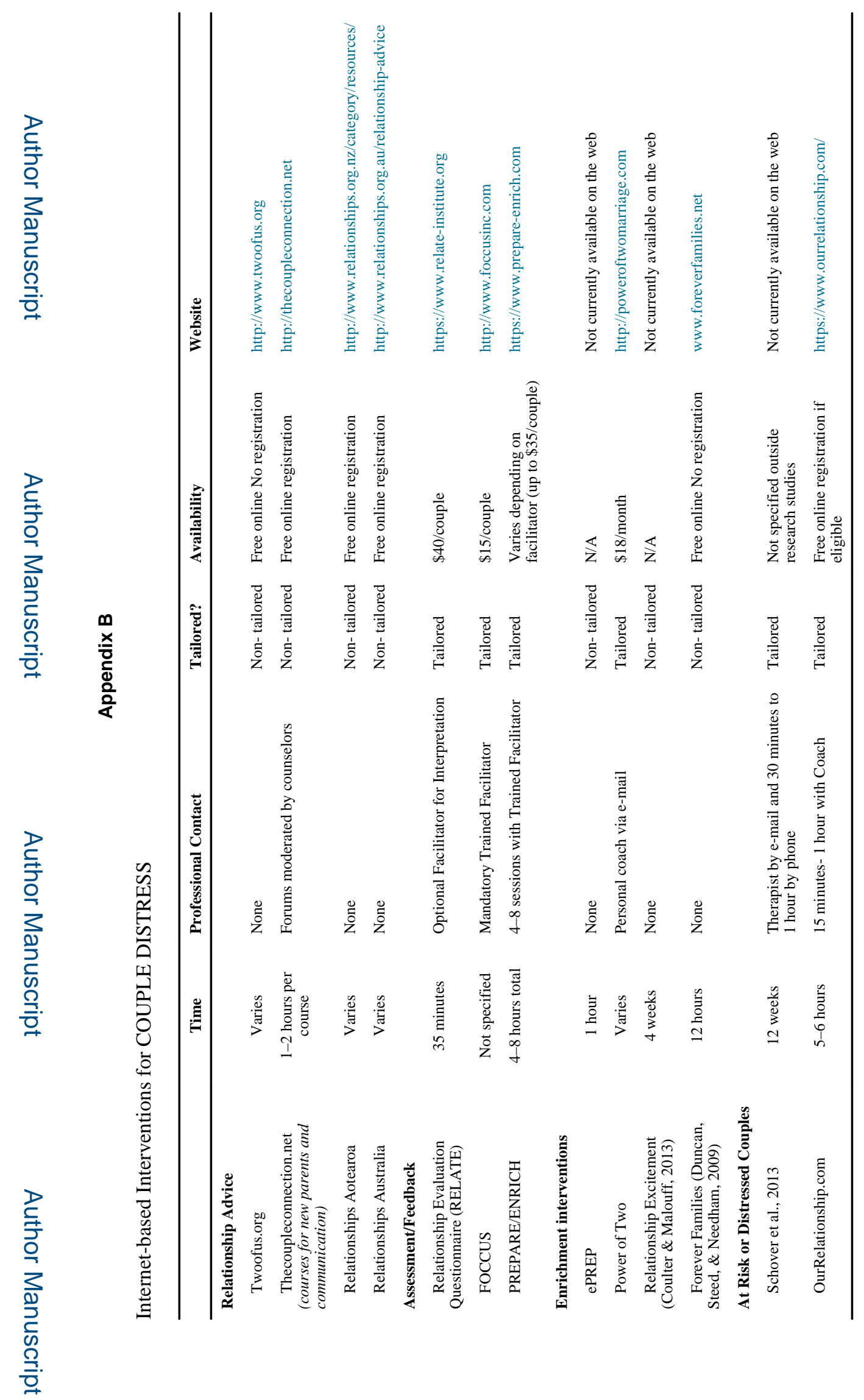

Aust N Z J Fam Ther. Author manuscript; available in PMC 2015 September 22. 


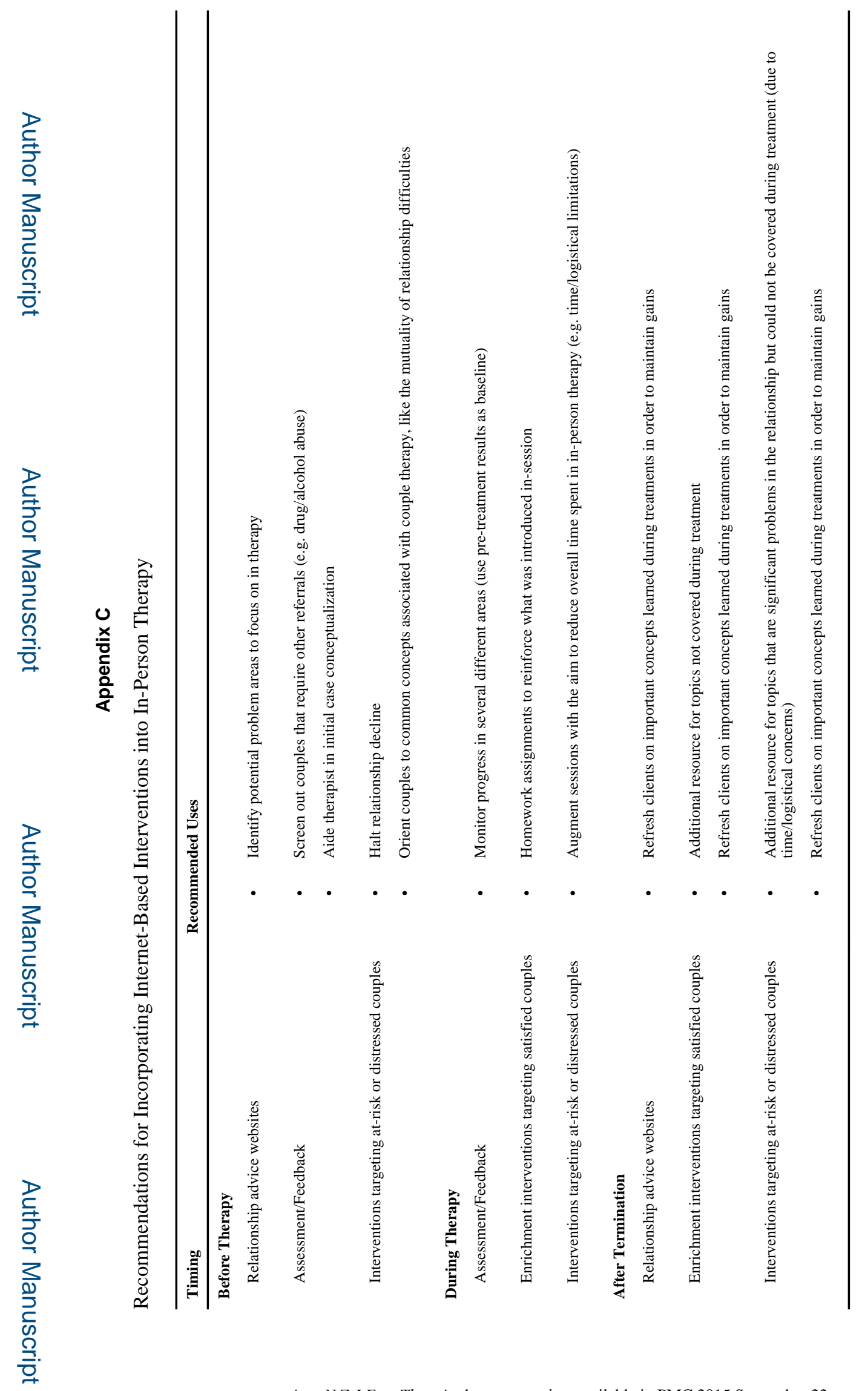

Aust N Z J Fam Ther. Author manuscript; available in PMC 2015 September 22. 